\title{
PRODUKSI BIODIESEL DARI LEMAK SAPI DENGAN PROSES TRANSESTERIFIKASI DENGAN KATALIS BASA NaOH
}

\author{
Ranggita Dwi Nindya Affandi, Toni Rizki Aruan, Taslim, Iriany \\ Departemen Teknik Kimia, Fakultas Teknik, Universitas Sumatera Utara, \\ Jl. Almamater Kampus USU Medan 20155, Indonesia \\ Email: affandi_ranggita@students.usu.ac.id
}

\begin{abstract}
Abstrak
Biodiesel merupakan bahan bakar alternatif yang biasanya dihasilkan dari minyak tumbuhan atau lemak hewan dengan menggunakan alkohol melalui proses transesterifikasi. Lemak sapi digunakan sebagai bahan baku transesterifikasi untuk menghasilkan biodiesel karena harga lemak sapi yang cukup murah di pasar dan untuk mengurangi polusi ke lingkungan. Dalam percobaan ini variabel yang diamati adalah suhu reaksi, waktu reaksi dan jumlah katalis. Transesterifikasi dilakukan didalam labu leher tiga yang telah dilengkapi dengan refluks kondensor, stirrer dan termometer. Pada penelitian ini telah digunakan lemak sapi sebagai bahan baku yang murah dan potensial untuk diproduksi menjadi biodiesel melalui proses transesterifikasi satu tahap. Dibawah kondisi optimal, yield maksimum dari biodiesel lemak sapi adalah 95,67\% yang didapat dengan menggunakan perbandingan molar lemak sapi : metanol $6: 1$ pada suhu $50{ }^{\circ} \mathrm{C}$ dengan waktu reaksi 30 menit dan katalis $\mathrm{NaOH}$ 0,8\%. Spesifikasi biodiesel telah sesuai dengan standar nasional Indonesia (SNI). Hasil yang diperoleh pada penelitian ini menunjukkan bahwa lemak sapi cocok digunakan sebagai bahan baku berbiaya murah untuk memproduksi biodiesel.
\end{abstract}

Kata kunci :biodiesel, transesterifikasi, lemak sapi, katalis

\begin{abstract}
Biodiesel is an alternative fuel commonly produced from vegetable oil or animal fat with methanol through transesterification. Beef tallow was used as a raw material of transesterification to make biodiesel, because the price of beef tallow was driven down by the market and to reduce the pollution to the surrounding. In this research variable observed were reaction temperature, reaction time and amount of catalyst. Transesterification was carried out in a three necked spherical Pyrex vessel equipped with reflux condenser, stirrer and thermometer. In the present investigation an attempt has been made to use beef tallow as low cost sustainable potential feedstock for biodiesel production by single step transesterification process. Under optimal condition, the maximum yield of 95,67\% beef tallow methyl ester was obtained by using $6: 1$ molar ratio of beef tallow to methanol at $50{ }^{\circ} \mathrm{C}$ for a reaction time 30 minutes in the presence of $0,8 \mathrm{wt} \%$ of $\mathrm{NaOH}$ catalyst. The biodiesel properties were comparable to Indonesian National Standard (SNI). The results of this work showed that the use of beef tallow is suitable for feedstock of biodiesel production with low cost.
\end{abstract}

Keywords : biodiesel, transesterification, beef tallow, catalyst

\section{Pendahuluan}

Pada saat ini bahan bakar minyak (BBM) yang ada di pasaran di sintesa dari produk petrokimia yang menggunakan bahan baku berasal dari minyak bumi. Ketersediaan minyak bumi sangat terbatas dan merupakan sumber daya alam yang tidak dapat diperbaharui, sehingga harganya akan semakin meningkat. Biodiesel merupakan sumber energi alternatif pengganti solar yang terbuat dari minyak tumbuhan atau lemak hewan. Biodiesel diperoleh dari reaksi minyak tanaman dan lemak hewan (trigliserida) dengan alkohol menggunakan katalis basa pada suhu dan 
komposisi tertentu sehingga dihasilkan dua zat yang disebut alkil ester (umumnya metil ester/ biodiesel) dan gliserol [1].

Lemak sapi dapat disimpan untuk waktu yang lama tanpa perlu pencegahan dan disimpan dalam tempat kedap udara untuk mencegah terjadinya oksidasi. Tabel 1 menunjukkan konsumsi produk hewan ternak per kapita pada tahun 2009 [2].

Tabel 1. Konsumsi produk hewan ternak per kapita (kg) pada tahun 2009

\begin{tabular}{|l|l|l|l|}
\hline \multicolumn{1}{|c|}{ Hewan } & \multicolumn{1}{|c|}{ Kg } & \multicolumn{1}{c|}{ Hewan } & \multicolumn{1}{c|}{ kg } \\
\hline Sapi & 1.18 & Kerbau & 0.12 \\
\hline Banteng & 0.09 & Babi & 0.55 \\
\hline Kambing & 0.15 & Ayam & 2.97 \\
\hline
\end{tabular}

Penelitian tentang produksi biodiesel dari limbah lemak sapi telah banyak dilakukan dalam beberapa tahun ini. Penelitian banyak dilakukan dengan berfokus pada proses esterifikasi. Penelitian ini bertujuan untuk meningkatkan ilmu pengetahuan, selain itu untuk (i) mempelajari produksi biodiesel dari lemak sapi dengan proses transesterifikasi katalis basa dan (ii) mengetahui kondisi terbaik dari proses transesterifikasi untuk mendapatkan yield metil ester tertinggi.

\section{Teori}

Biodiesel merupakan bahan bakar alternatif yang terbuat dari bahan baku yang dapat diperbaharui seperti minyak tanaman dan lemak hewan. Biasanya biodiesel dibuat dengan reaksi transesterifikasi dimana digunakan katalis dan alkohol untuk memperoleh biodiesel dan gliserol. Katalis biasanya digunakan untuk meningkatkan kecepatan reaksi dan yield [3]. Katalis yang biasa digunakan dalam reaksi transesterifikasi adalah katalis basa seperti kalium hidroksida $(\mathrm{KOH})$ dan natrium hidroksida $(\mathrm{NaOH})[4]$.

Proses pembuatan biodiesel dari minyak tumbuhan dan lemak hewan yang mempunyai asam lemak bebas tinggi harus melalui proses esterifikasi terlebih dahulu. Bahan baku untuk proses transesterifikasi harus memiliki angka asam lemak bebas <2\% [10]. Lemak sapi yang digunakan mempunyai asam lemak bebas sebesar 0,50\% sehingga dapat dilakukan proses transesterifikasi langsung.

Reaksi transesterifikasi adalah reaksi bolak balik (reversible), oleh karena itu digunakan jumlah alkohol berlebih untuk menggeser kesetimbangan ke arah produk [3]. Gambar 1 menunjukkan reaksi transesterifikasi.

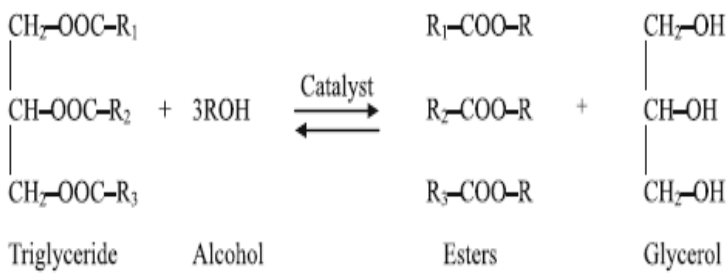

\section{Gambar 1. Reaksi Transesterifikasi dari Trigliserida}

Secara stoikiometri jumlah alkohol yang dibutuhkan untuk 1 mol trigliserida adalah $3 \mathrm{~mol}$ alkohol sehingga diperoleh 3 mol alkil ester dan 1 mol gliserol [6].

Produk samping dari reaksi pembentukan biodiesel ini adalah gliserol. Proses pembentukan biodiesel ini mengurangi viskositas dari produk akhir. Transesterifikasi sangat luas digunakan untuk mengurangi viskositas minyak tanaman [3].

Alkohol yang biasa digunakan dalam proses transesterifikasi adalah metanol akan tetapi etanol juga dapat digunakan namun mempunyai harga yang lebih mahal [5]. Perbandingan rasio molar lemak sapi terhadap metanol 6:1 yang paling sering digunakan dalam proses industri yang menghasilkan konversi >98\% [6].

\section{Metodologi Penelitian}

Bahan baku yang digunakan dalam penelitian ini adalah lemak sapi dan bahan kimia berupa metanol dan natrium hidroksida $(\mathrm{NaOH})$. Lemak sapi dimasak untuk mendapatkan minyak dan dikeringkan pada suhu $110 \quad{ }^{\circ} \mathrm{C}$ untuk 
menghilangkan kandungan air dari minyak. Minyak lemak sapi kemudian disaring dan disimpan dalam tempat yang kedap udara untuk menghindari terjadinya oksidasi minyak. Minyak lemak sapi kemudian dianalisa kandungan air, kadar asam lemak bebas dan komponen asam lemak didalamnya. Pada tabel 2 ditunjukkan kandungan asam lemak dalam lemak sapi.

Tabel 2. Kandungan Asam Lemak dalam Lemak Sapi yang diukur menggunakan Gas Chromatography (GC)

\begin{tabular}{|l|l|l|}
\hline \multicolumn{1}{|c|}{ Asam Lemak } & Struktur & \% berat \\
\hline Asam Kaprilat & C 10 & 0,0958 \\
\hline Asam Laurat & C 12 & 0,5516 \\
\hline Asam Miristat & C 14 & 8,7588 \\
\hline Asam Miristoleinat & C $14: 1$ & 0,8933 \\
\hline Asam Palmitat & C 16 & 33,8750 \\
\hline Asam Palmitoleat & C $16: 1$ & 2,3073 \\
\hline Asam Heptadekanoat & C 17 & 1,2651 \\
\hline Asam Stearat & C 18 & 21,4603 \\
\hline Asam Oleat & C $18: 1$ & 29,5983 \\
\hline Asam Linoleat & C $18: 2$ & 0,8967 \\
\hline Asam $\alpha$ Linolenat & C $18: 3$ & 0,1163 \\
\hline Asam Arasidat & C 20 & 0,1754 \\
\hline
\end{tabular}

Proses transesterifikasi dilakukan di dalam labu leher tiga yang telah dilengkapi dengan refluks kondensor, stirrer dan termometer. Rangkaian peralatan transesterifikasi dapat dilihat pada gambar 2. Percobaan ini menggunakan 150 gram lemak sapi dengan suhu reaksi $50-60{ }^{\circ} \mathrm{C}$, waktu reaksi 30-60 menit, konsentrasi katalis 0,8-1,2\% berat dan perbandingan molar metanol terhadap lemak sapi adalah 6:1.

Metanol yang digunakan terlebih dahulu harus dicampur dengan natrium hidroksida $(\mathrm{NaOH})$ sebelum di masukkan ke dalam minyak. Setelah reaksi selesai, campuran dimasukkan ke dalam corong pemisah untuk memisahkan antara gliserol (lapisan bawah) dan metil ester (lapisan atas). Metil ester yang diperoleh dicuci dengan air panas 85 ${ }^{\circ} \mathrm{C}$ hingga pH metil ester netral.

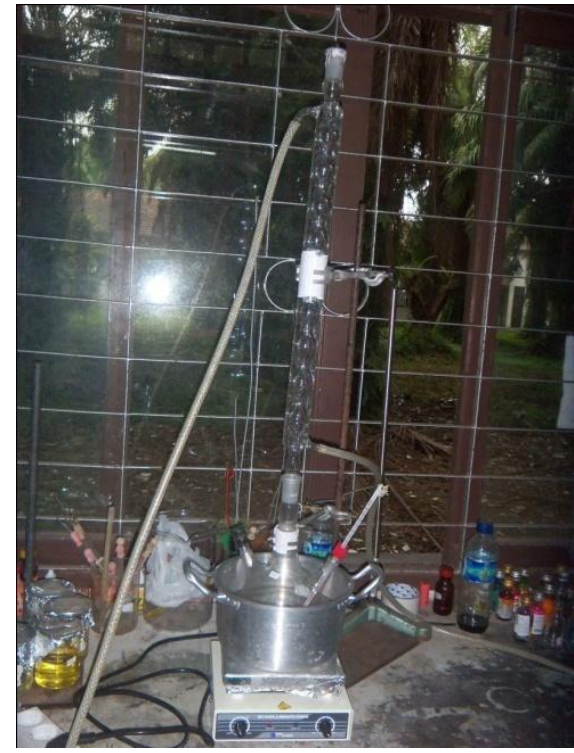

Gambar 2. Rangkaian Peralatan Transesterifikasi

Hasil yang diperoleh kemudian diuji seperti uji viskositas, densitas, kemurnian, titik nyala sesuai dengan standar nasional Indonesia (SNI) [7], yang ditunjukkan pada tabel 3.

Tabel 3. Persyaratan kualitas biodiesel menurut SNI

\begin{tabular}{|l|l|}
\hline \multicolumn{1}{|c|}{ Parameter } & \multicolumn{1}{c|}{ Standar } \\
\hline Densitas pada $40^{\circ} \mathrm{C}, \mathrm{kg} / \mathrm{m}^{3}$ & $850-890$ \\
\hline $\begin{array}{l}\text { Viskositas kinematik pada } \\
40^{\circ} \mathrm{C}, \mathrm{cSt}\end{array}$ & $2,3-6,0$ \\
\hline Titik nyala, ${ }^{\circ} \mathrm{C}$ & Min 100 \\
\hline Kadar ester alkil, $\%$ & Min 96,5 \\
\hline
\end{tabular}

Hasil

Pengaruh Suhu Reaksi terhadap Yield Biodiesel

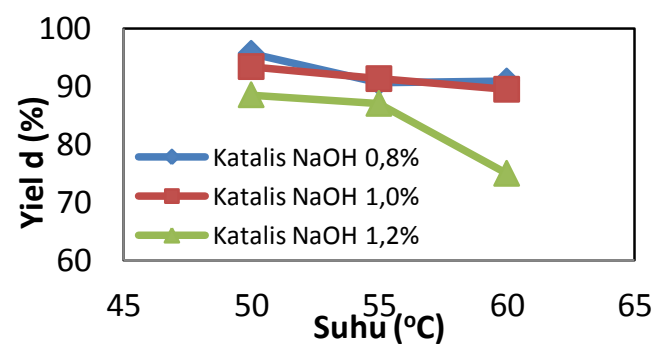

Gambar 3. Hubungan antara suhu reaksi dengan yield biodiesel pada waktu reaksi 30 menit

Hubungan antara suhu reaksi terhadap yield biodiesel dengan berbagai variasi konsentrasi katalis pada waktu tetap 30 menit dapat dilihat 
pada gambar 3. Suhu reaksi sangat mempengaruhi reaksi dan yield biodiesel yang dihasilkan. Dari gambar 3 dapat dilihat bahwa peningkatan suhu dari 50 menjadi $55{ }^{\circ} \mathrm{C}$ dapat menurunkan yield biodiesel.

Suhu reaksi yang berlebih akan menurunkan yield biodiesel karena suhu reaksi yang mendekati titik didih metanol kemungkinan besar metanol akan menguap. Katalis yang berlebih akan mengakibatkan asam lemak bereaksi dengan katalis menjadi sabun sehingga akan mempersulit pencucian metil ester dan menurunkan yield. Pada suhu $50{ }^{\circ} \mathrm{C}$ sudah banyak terbentuk lapisan metil ester dan sedikit lapisan gliserol. Ini berarti bahwa pada suhu $50{ }^{\circ} \mathrm{C}$ jumlah metanol yang digunakan belum ada yang hilang akibat adanya penguapan atau habis bereaksi.

Suhu terbaik yang memberikan yield tertinggi didapat pada suhu $50{ }^{\circ} \mathrm{C}$, waktu 30 menit dengan konsentrasi katalis $0,8 \%$ yang memberikan yield sebesar $95,67 \%$.

\section{Pengaruh Waktu Reaksi terhadap Yield Biodiesel}

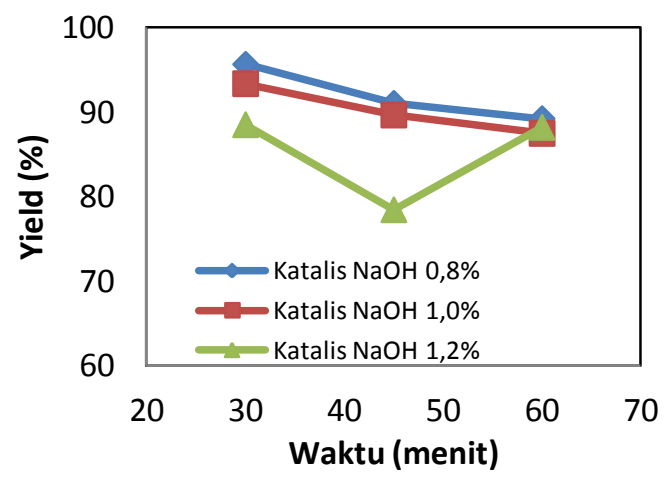

Gambar 4. Hubungan antara waktu reaksi dengan yield biodiesel pada suhu reaksi $50^{\circ} \mathrm{C}$

Hubungan antara waktu reaksi terhadap yield biodiesel dengan berbagai variasi konsentrasi katalis pada suhu tetap $50{ }^{\circ} \mathrm{C}$ dapat dilihat pada gambar 4. Peningkatan waktu reaksi dari 30 menit menjadi 45 menit menyebabkan pengurangan jumlah yield. Pada waktu 30 menit, reaksi sudah berjalan dengan cepat. Selanjutnya peningkatan waktu reaksi akan menyebabkan yield berkurang karena adanya reaksi balik yaitu metil ester yang terbentuk kembali menjadi trigliserida.

Pada awal reaksi, reaksi transesterifikasi tergantung pada pencampuran dan penyebaran alkohol ke dalam minyak, reaksi berlangsung sangat cepat. Waktu reaksi yang berlebih akan menimbulkan pengurangan jumlah yield akibat reaksi balik transesterifikasi, sehingga jumlah ester berkurang dan juga menyebabkan banyaknya asam lemak yang membentuk sabun [8].

\section{Pengaruh Katalis terhadap Yield Biodiesel}

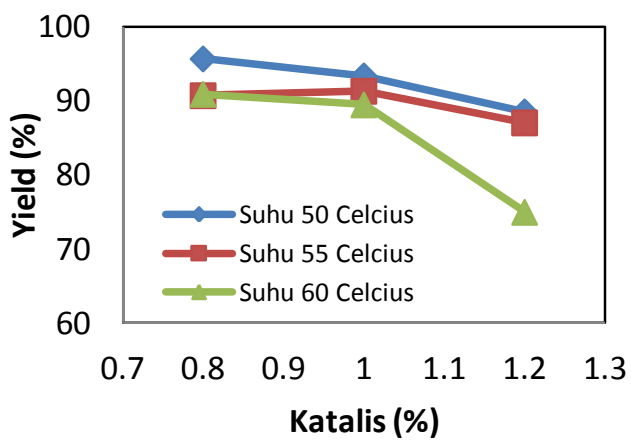

Gambar 5. Hubungan antara konsentrasi katalis dengan yield biodiesel pada waktu 30 menit

Hubungan antara konsentrasi katalis terhadap yield biodiesel dengan berbagai variasi suhu pada waktu tetap 30 menit dapat dilihat pada gambar 5.

Dari gambar 5 dapat dilihat bahwa semakin besar konsentrasi katalis $\mathrm{NaOH}$ yang digunakan maka jumlah yield yang dihasilkan akan semakin kecil atau mengalami penurunan. Penurunan yield biodiesel tergantung dari penggunaan katalis basa berlebih yang menyebabkan banyak trigliserida yang bereaksi dengan katalis basa dan membentuk banyak sabun [8]. Sabun akan meningkatkan kelarutan metil ester di dalam gliserol dan membentuk emulsi ester dan gliserol sehingga akan menyulitkan di dalam pemisahan ester [9]. Hal ini sesuai dengan percobaan yang dilakukan dimana pada konsentrasi katalis tinggi campuran hasil transesterifikasi keruh karena terbentuknya banyak 
sabun dan jumlah gliserol yang didapat sangat banyak.

Kondisi terbaik yang didapatkan adalah pada suhu $50{ }^{\circ} \mathrm{C}$, waktu 30 menit dan konsentrasi katalis $0,8 \%$.

\section{Analisis Densitas}

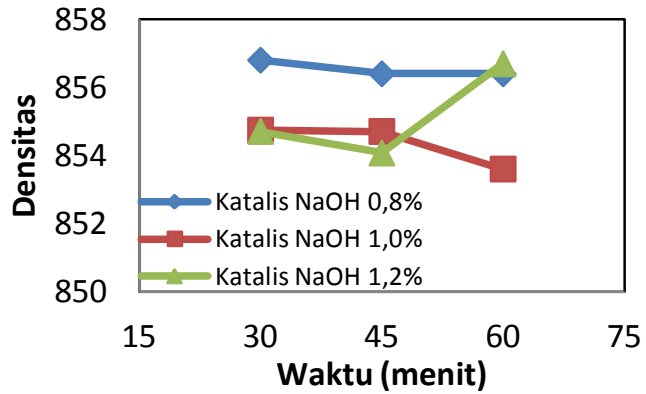

Gambar 6. Hubungan antara waktu reaksi dengan densitas biodiesel pada suhu reaksi $50^{\circ} \mathrm{C}$

Hubungan antara waktu reaksi terhadap densitas biodiesel dengan berbagai variasi konsentrasi katalis pada suhu tetap $50{ }^{\circ} \mathrm{C}$ dapat dilihat pada gambar 6. Data-data densitas tersebut diukur dengan piknometer pada kondisi suhu $40{ }^{\circ} \mathrm{C}$. Metil ester memiliki densitas yang lebih rendah dibandingkan dengan trigliserida (lemak sapi).

Densitas adalah perbandingan antara bobot dan volume, yaitu sifat yang tidak bergantung pada banyaknya bahan. Penurunan nilai densitas akan menyebabkan nilai viskositas semakin kecil [11]. Densitas dipengaruhi oleh tahap pemurnian karena tahap pemurnian yang kurang baik dapat menyebabkan densitas biodiesel mempunyai densitas bervariasi.

Menurut Standar Nasional Indonesia (SNI 047182-2006) densitas biodiesel pada suhu $40{ }^{\circ} \mathrm{C}$ adalah $850-890 \mathrm{~kg} / \mathrm{m}^{3}$. Dari hasil penelitian untuk berbagai variasi yang dilakukan diperoleh densitas berkisar 854-857 kg/m $\mathrm{m}^{3}$. Dengan demikian biodiesel yang diperoleh telah memenuhi standar densitas biodiesel.

\section{Analisis Viskositas}

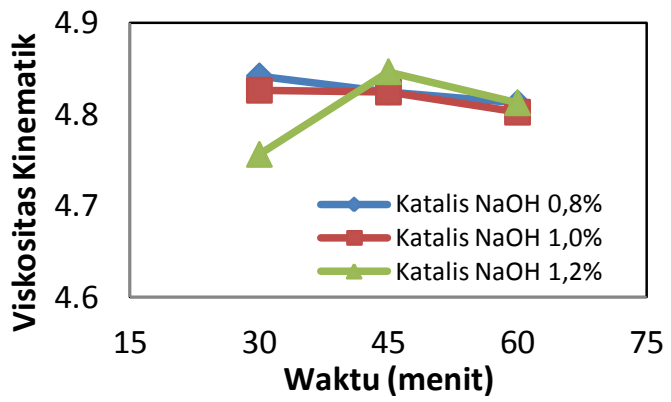

Gambar 7. Hubungan antara waktu reaksi dengan viskositas biodiesel pada suhu reaksi $5^{\circ} \mathrm{C}$

Hubungan antara waktu reaksi terhadap viskositas biodiesel dengan berbagai variasi konsentrasi katalis pada suhu tetap $50{ }^{\circ} \mathrm{C}$ dapat dilihat pada gambar 7. Data-data viskositas tersebut diukur dengan viskosimeter pada kondisi suhu 40 ${ }^{\circ} \mathrm{C}$. Viskositas merupakan tahanan yang dimiliki fluida yang dialirkan dalam pipa kapiler pada gaya gravitasi atau daya alir. Kecepatan mengalir juga tergantung pada massa jenis maka pengukuran ini dinyatakan dengan viskositas kinematik [11]. Salah satu tujuan transesterifikasi trigliserida menjadi metil ester adalah untuk menurunkan viskositas trigliserida.

Menurut Standar Nasional Indonesia (SNI 047182-2006), viskositas kinematik biodiesel adalah 2,3 - 6,0 cSt. Dari hasil penelitian untuk berbagai variasi yang dilakukan diperoleh viskositas kenematik berkisar 4,7 - 4,9 cSt. Nilai viskositas biodiesel mengalami penurunan dengan semakin lamanya waktu reaksi dan semakin meningkatnya suhu [11]. Dengan demikian, biodiesel yang diperoleh masih memenuhi standar viskositas kinematik biodiesel.

\section{Kesimpulan}

Lemak sapi merupakan limbah industri makanan yang akan menyebabkan kerusakan lingkungan bila langsung dibuang. Oleh karena itu lemak sapi dapat diolah menjadi biodiesel yang 
mempunyai harga jual. Waktu reaksi terbaik didapatkan pada 30 menit, suhu reaksi $50{ }^{\circ} \mathrm{C}$ dan konsentrasi katalis $0,8 \%$ yang akan menghasilkan yield sebesar 95,67\%. Peningkatan suhu reaksi dan waktu reaksi tidak akan meningkatkan jumlah yield biodiesel yang dihasilkan. Konsentrasi katalis yang berlebih akan menyebabkan terbentuknya reaksi penyabunan sehingga mengurangi yield yang dihasilkan.

\section{Daftar Pustaka}

[1] PT. Kreatif Indonesia, Biodiesel, www. indobiofuel.com, 2006, diakses pada 20 Desember 2012

[2] Stanton, Emms dan Sia, Competitive Industry Report on the Indonesian Cattle and Goats Sectors-Opportunities for Canadian Animal Genetics, www.ats-sea.agr.gc.ca/ase/5675-eng. htm, Singapore, 2010, diakses pada 18 Agustus 2012

[3] Demirbas, Ayhan, Biodiesel, A Realistic Fuel Alternative for Diesel Engines, Springer, Turkey, 2008.

[4] Hikmah, Maharani dan Zuliyana, Pembuatan Metil Ester (Biodiesel) dari Minyak Dedak Padi dan Metanol dengan Proses Esterifikasi dan Transesterifikasi, Artikel Ilmiah Universitas Diponegoro, Semarang, 2010.

[5] Van Gerpen, Jon, Biodiesel Production, Improvement of Crop Plants for Industrial End Uses, Springer, The Netherlands, p. 281-289, 2007

[6] Freedman, B., Pryde, E.H., Mounts, T.L, Variable Affecting the yields of Fatty Esters from Transesterified Vegetable Oils, J.Am.Oil Chem.Soc, Vol 61, p 1638-1643,1984.

[7] Badan Standarisasi Nasional, Persyaratan Kualitas Biodiesel, www.bsn.com, 2006, diakses pada 18 Agustus 2012.
[8] Leung, D.Y.C., Wu, X., Leung, M.K.H. A, Review on Biodiesel Production Using Catalyzed Transesterification, Applied Energy, Vol. 87, p 1083-1095, 2010.

[9] Atapour, Mehdi dan Kariminia, Hamid Reza, Characterization and Transesterification of Iranian Bitter Almond Oil for Biodiesel Production, Applied Energy, Vol 88, p 23772381, 2011.

[10] Ramadhas, A.S., Mulareedharan, C. dan Jayaray, S, Performance and Emission Evaluation of Diesel Engine Fueled with Methyls Esteres of Rubber Seed Oil, Renewable Energy, Filipina, 2005.

[11] Wahyuni, Ade, Karakterisasi Mutu Biodiesel dari Minyak Kelapa Sawit berdasarkan Perlakuan Tingkat Suhu yang berbeda menggunakan Reaktor Sirkulasi, http: www. scribd.com/doc /44827668/ Pengaruh Suhu dan Waktu Terhadap Kualitas Biodiesel, 2010, diakses pada 18 Agustus 2012. 